\title{
The Occlutech Duct Occluder for Patent Ductus Arteriosus
}

\section{A Retrospective Case Series}

\author{
Najib Hanna, MD ${ }^{1}$, Ramy Charbel, MD²*, Ghassan Chehab, MD', Bernard Gerbaka, MD², \\ Zakhia Saliba, MD ${ }^{1}$ \\ ${ }^{1}$ Hotel-Dieu de France University Medical Center, Department of Pediatric Cardiology, Saint Joseph University, Naccache Boulevard, \\ Achrafieh, Lebanon \\ ${ }^{2}$ Hotel-Dieu de France University Medical Center, Department of Pediatrics, Saint Joseph University, Naccache Boulevard, Achrafieh, \\ Lebanon
}

\begin{abstract}
Objective: To describe our experience in percutaneous patent ductus arteriosus (PDA) closure using the Occlutech Duct Occluder (ODO).

Methods: We retrospectively reviewed records of patients who underwent a PDA closure attempt using the ODO between August 2013 and October 2015. Only patients with isolated PDA and weighing $\geq 6$ kg were eligible for ODO use.

Results: Eighteen ODO devices were successfully implanted in 18 patients. Patient age and weight ranged from 6 to 180 months (median, 23.5 months) and 6 to $54 \mathrm{~kg}$ (median, $11 \mathrm{~kg}$ ), respectively. PDAs were of type $\mathbf{A}(n=16)$, type $\mathbf{E}(n=1)$, or type $\mathbf{D}(n=1)$. PDA diameter ranged from 2 to $5 \mathrm{~mm}$ (median, $3 \mathrm{~mm}$ ). Median procedure time was 55 min (range, 35-105 min). Median fluoroscopy time was $9.2 \mathrm{~min}$ (range, 3.0-29.6 min). The device diameter (pulmonary end) was 5-8 mm (median, $7 \mathrm{~mm}$ ). The standard shank length was used in 13 cases, and the long variant was used in five cases. Median follow-up period was 12 months. All devices were successfully implanted. Total occlusion was achieved the following day in all but two patients, in whom it was confirmed one month later. No major complications occurred. Mild pulmonary obstruction was noted in one patient, and aortic disc bulging occurred in two patients without hemodynamic consequences.

Conclusion: In this group of patients, the ODO showed excellent results in terms of safety and efficacy. The
\end{abstract}

ax +1 2037853346

E-Mail: jshd@scienceinternational.org

http://structuralheartdisease.org/ (c) 2017 Journal of Structural Heart Disease Published by Science International Corp. ISSN 2326-4004

Accessible online at:

http://structuralheartdisease.org/ long device variant may be advantageous in some large and long PDAs. Larger case series are needed to compare the ODO with preexisting devices.

Copyright @ 2017 Science International Corp.

\section{Key Words}

Congenital heart disease - Patent ductus arteriosus • Percutaneous closure $\cdot$ Occlutech

\section{Introduction}

Since the first successful transcatheter closure of patent ductus arteriosus (PDA) by Porstmann in 1967 $[1,2]$, several different PDA closure devices have been developed and evaluated. Today, percutaneous closure of almost any PDA beyond neonatal age can be easily and safely performed using detachable coils or specifically designed occluders, including different generations of the Amplatzer Duct Occluder (ADO I, II, and AS) [3-5]. Nevertheless, some large and long (i.e., "slow tapering") type A PDAs and nonconical large PDAs still pose technical difficulties to the interventionist, especially in small infants.

A new device, the Occlutech Duct Occluder (ODO), has been designed with the aim of addressing some of these challenges. Like the ADO I, the ODO is constructed from braided Nitinol wires, has an aortic

* Corresponding Author:

Ramy Charbel, MD Department of Pediatrics

Hotel-Dieu de France University Medical Center, Saint Joseph University Naccache Boulevard, Achrafieh, Lebanon

Tel.: +961 3783 560, Fax: +961 1615300 ext. 3233, E-Mail: ramycharbel@hotmail.com 
Table 1. Comparative table showing characteristics of available Occlutech Duct Occluder devices (manufacturer data).

\begin{tabular}{llllll}
\hline Shank Type & $\begin{array}{l}\text { Introducing } \\
\text { System Size }(\mathbf{m m})\end{array}$ & $\begin{array}{l}\text { Aortic Shank } \\
\text { Diameter }(\mathbf{m m})\end{array}$ & $\begin{array}{l}\text { Pulmonic Shank } \\
\text { Diameter }(\mathbf{m m})\end{array}$ & $\begin{array}{l}\text { Retention Disc } \\
\text { Diameter }(\mathbf{m m})\end{array}$ & $\begin{array}{l}\text { Length }(\mathbf{m m}) \\
\text { Standard shank }\end{array}$ \\
\hline Standard shank & 6 & 3.5 & 5 & 9 & 4.25 \\
Standard shank & 6 & 4 & 6 & 10 & 5.00 \\
Standard shank & 6 & 5 & 7 & 11 & 6.05 \\
Standard shank & 7 & 6 & 8 & 13 & 6.30 \\
Standard shank & 7 & 8 & 10 & 16 & 7.00 \\
Standard shank & 8 & 10 & 12 & 20 & 12.00 \\
Standard shank & 9 & 12 & 15 & 24 & 14.00 \\
Long shank & 6 & 14 & 18 & 9 & 16.00 \\
Long shank & 6 & 3.5 & 5 & 10 & 7.00 \\
Long shank & 6 & 4 & 6 & 11 & 7.50 \\
Long shank & 6 & 5 & 7 & 13 & 8.50 \\
Long shank & 7 & 6 & 8 & 16 & 9.00 \\
\hline
\end{tabular}

$\mathrm{mm}=$ millimeters.

retention disc, and is attached to its delivery cable using a screw cap mechanism. Both devices have comparable designs; however, the ODO has a waist that is wider at its pulmonary end than at its aortic end with the purpose of achieving a more stable implant. Moreover, to facilitate use in longer PDAs, the

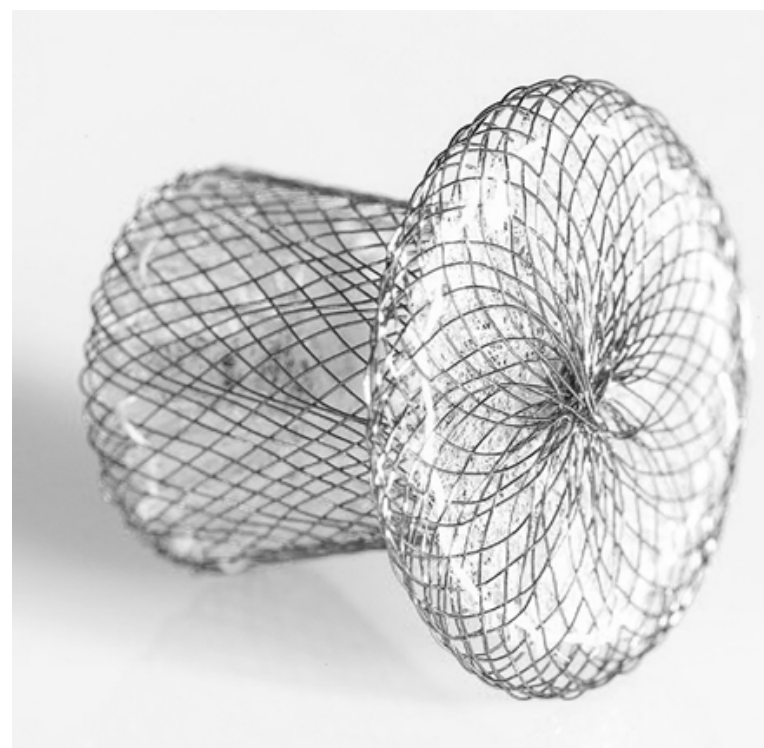

Figure 1. The Occlutech Duct Occluder device (as shown on occlutech.com).
ODO is available in two different lengths.

The objective of this study was to investigate the safety, efficacy, and clinical utility of the ODO device.

\section{Materials and Methods}

The ODO was introduced to our catheterization unit in August 2013. Since then, our policy has been to prioritize its use over other existing devices in patients with isolated PDA who weigh $\geq 6 \mathrm{~kg}$ to test its safety and efficacy. We retrospectively reviewed records of patients who underwent a PDA closure attempt with the ODO between August 2013 and October 2015.

\section{The Device}

The ODO device is made of braided Nitinol threads. Nitinol is a very elastic metal alloy with memory properties. The ODO consists of an aortic disc connected to a cone-shaped shank (Figure 1). Compared with the ADO I device, the direction of the ODO conical body is inverted. The proximal end of the shank (i.e., pulmonic end) has a diameter that is $1.5-2.0 \mathrm{~mm}$ larger than that of its aortic end, and the retention disc has a diameter that exceeds the size of the aortic end of the shank by $5.5-8.0 \mathrm{~mm}$. The ODO is available in several sizes, each with a standard (i.e., short) or long shank (Table 1). Polyethylene patches inside the device support immediate closure of the defect. The device is attached to a delivery cable by a screw that, after detachment, protrudes from the pulmonary end of the device to allow easier snaring if retrieval is required. Before January 2015, and because the ODO did not yet have a dedi- 


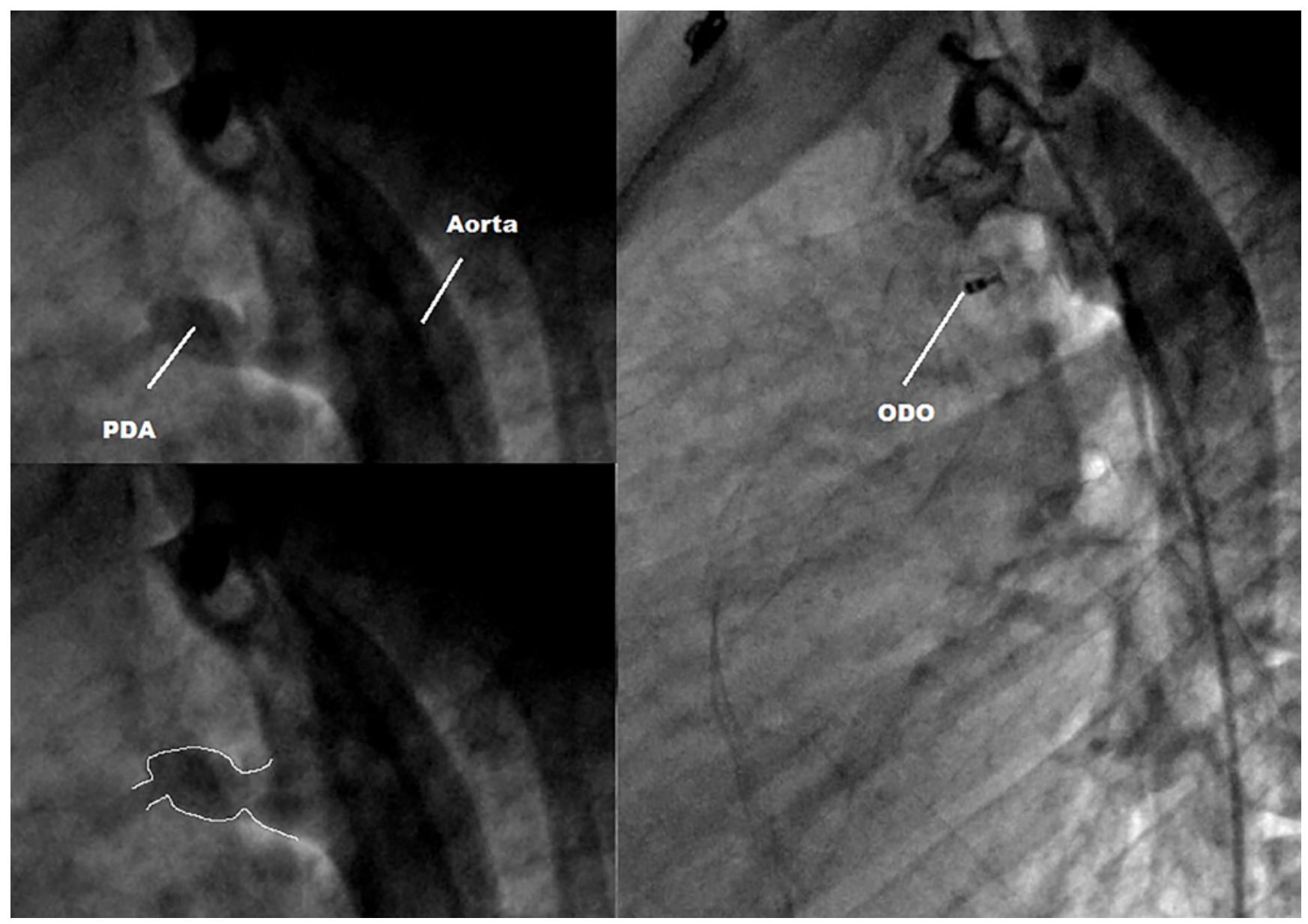

Figure 2. In a 15-year-old female weighing $54 \mathrm{~kg}$, the long variant of the 5-7 Occlutech Duct Occluder was adequately accommodated in a 3-mm type D patent ductus arteriosus.

cated sheath, a Mullins sheath (William Cook Europe, Bjæverskov, Denmark) was used to deploy the device. Since then, a dedicated delivery set including a delivery sheath (6-F to 9-F depending on the implant size), hemostasis valve, dilator, and transparent loader was introduced.

\section{Technique}

Informed consent was obtained prior to patient enrollment. All procedures were performed according to the manufacturer's instructions under general anesthesia by the same operator (ZS). In brief, vascular access was obtained via the femoral artery and vein. Heparin $(50 \mathrm{l} \mathrm{U} / \mathrm{kg}$ ) and Cefazolin (30 $\mathrm{mg} / \mathrm{kg}$ ) were administered intravenously. Lateral aortography was performed to determine the size and shape of the PDA. In some patients, supplementary projections were needed to more accurately delineate the PDA. In PDAs $>3 \mathrm{~mm}$, systolic and diastolic diameter variations were carefully measured to determine the maximal diameter of the narrowest PDA segment (i.e., "landing zone") during cardiac cycling. The device size was calculated to fit the diameter of the area where the device was to be "squeezed" into the PDA. For ODO size selec- tion, the aortic end of the device shank was sized to be 1-2 $\mathrm{mm}$ larger than the landing zone in smaller PDAs $(<3 \mathrm{~mm})$ and 2-3 mm larger in larger PDAs ( $\geq 3 \mathrm{~mm}$ ). The standard ODO variant was used in patients with short PDAs. Use of the long ODO variant was limited to cases in which the operator judged that the pulmonary part of the device would not reach the narrowest part of the duct into the pulmonary artery. Venous delivery was used in all cases.

Before releasing the device, an aortogram to verify device positioning was performed. Additionally, if the device appeared to protrude into the pulmonary artery or the aorta, pulmonary or aortic pullback pressure tracing and angiography were performed to rule out significant obstruction. Repositioning was judged necessary in some cases, but we did not encounter any difficulty in resheathing and redeploying the device in a more suitable manner. After a satisfying position was achieved, the device was released by rotating the delivery cable in a counter-clockwise manner. A final aortogram was performed after the release of the ODO to confirm the position of the device and check for residual shunt or aortic obstruction. 


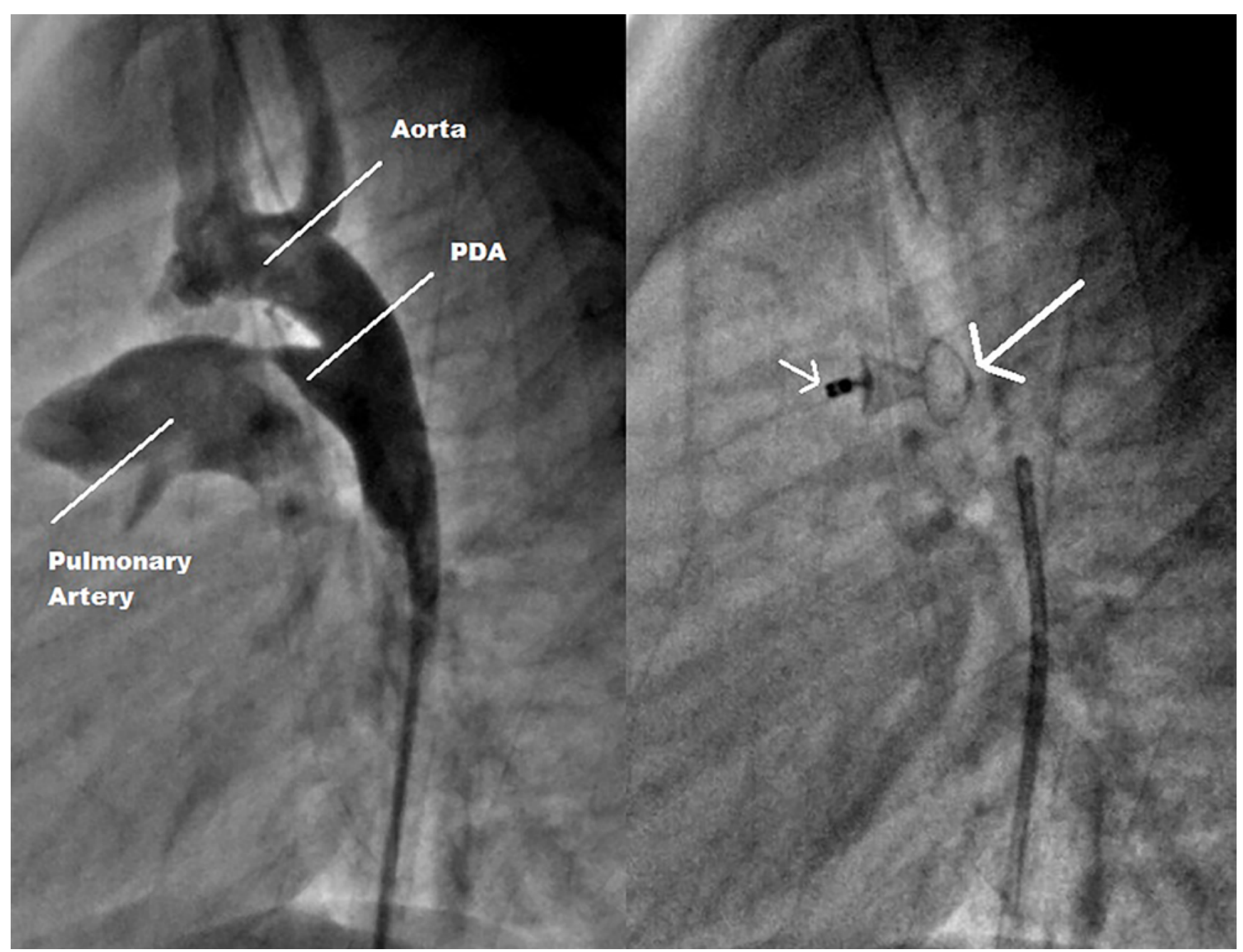

Figure 3. In a 19-month-old boy weighing $10 \mathrm{~kg}$, a 3-mm type A "slow tapering" patent ductus arteriosus was closed using a 5-7 Occlutech Duct Occluder standard shank. The thick arrow shows bulging of the aortic disc, probably due to excessive oversizing. Note the screw pin deformation (thin arrow), which was related to the forced entry of the device in an incompatible delivery system after multiple attempts due to the lack of a dedicated delivery system at the time.

All 18 patients were discharged 24 hours following the procedure. The following day, chest x-rays (anteroposterior and lateral) and Doppler echocardiography were obtained before discharge. Special attention was paid to residual shunts and left pulmonary or aortic isthmic obstruction. Urinalysis was performed only in cases of residual shunting. Patients were scheduled for cardiology consultation and echocardiography at 10 days and at $1,3,6$, and 12 months.

\section{Statistical Analysis}

Results are expressed as percentages and median values.

\section{Results}

The median age of the 18 patients was 23.5 months (range, 6-180 months), and median weight was 11 $\mathrm{kg}$ (range, 6-54 kg). All patients had isolated PDAs. Table 2 summarizes the basic characteristics of the patients and procedure-related parameters according to PDA morphology. The PDA shape was type A "fast tapering" in seven patients (40\%), type A "slow tapering" in nine patients (50\%), type $E$ in one patient, and type $D$ in one patient. The narrowest PDA diameter ranged from 2 to $5 \mathrm{~mm}$ (median, $3 \mathrm{~mm}$ ). Median procedure time was $55 \mathrm{~min}$ (range, 35-105 min), and median fluoroscopy time was 9.19 min (range, 3-29.57 min). Device diameters (aortic end) ranged from 3.5 to $6 \mathrm{~mm}$ (median, $5 \mathrm{~mm}$ ); standard device variants were used in 13 patients, and long devices were used in five patients. The median follow-up period was 12 
Table 2. Characteristics of patients and procedure-related parameters according to patent ductus arteriosus morphology.

\begin{tabular}{|c|c|c|c|c|c|c|c|c|c|}
\hline Patient ID & Gender & $\begin{array}{l}\text { Age } \\
\text { (months) }\end{array}$ & $\begin{array}{l}\text { Weight } \\
\text { (kg) }\end{array}$ & \multicolumn{2}{|c|}{$\begin{array}{l}\text { PDA Size } \\
(\mathrm{mm})\end{array}$} & $\begin{array}{l}\text { Fluoroscopy } \\
\text { Time (min) }\end{array}$ & $\begin{array}{l}\text { Pulmonic } \\
\text { Shank } \\
\text { Diameter } \\
(\mathrm{mm})\end{array}$ & $\begin{array}{l}\text { Aortic } \\
\text { Shank } \\
\text { Diameter } \\
(\mathrm{mm})\end{array}$ & Shank \\
\hline \multicolumn{10}{|c|}{ Type A fast PDA } \\
\hline ZS-PDA01 & $\mathrm{F}$ & 48 & 15.0 & 2.3 & 35 & 3.16 & 6.0 & 4.0 & Standard \\
\hline ZS-PDA02 & F & 6 & 6.5 & 5.0 & 60 & 10.13 & 7.0 & 5.0 & Standard \\
\hline ZS-PDA03 & $\mathrm{F}$ & 7 & 10.0 & 3.5 & 40 & 3.12 & 8.0 & 6.0 & Standard \\
\hline ZS-PDA04 & $F$ & 72 & 21.0 & 2.5 & 60 & 14.14 & 6.0 & 4.0 & Standard \\
\hline ZS-PDA05 & F & 12 & 6.0 & 2.8 & 35 & 5.27 & 7.0 & 5.0 & Standard \\
\hline ZS-PDA06 & $\mathrm{F}$ & 13 & 12.0 & 3.3 & 53 & 6.50 & 7.0 & 5.0 & Standard \\
\hline ZS-PDA18 & $\mathrm{F}$ & 60 & 17.0 & 5.0 & 35 & 3.00 & 8.0 & 6.0 & Standard \\
\hline \multicolumn{10}{|c|}{ Type A slow PDA } \\
\hline ZS-PDA07 & $\mathrm{F}$ & 8 & 9.5 & 3.0 & 55 & 18.70 & 7.0 & 5.0 & Long \\
\hline ZS-PDA08 & $\mathrm{F}$ & 27 & 9.0 & 3.0 & 40 & 13.47 & 7.0 & 5.0 & Standard \\
\hline ZS-PDA10 & M & 19 & 10.0 & 3.0 & 55 & 3.18 & 7.0 & 5.0 & Standard \\
\hline ZS-PDA11 & $\mathrm{F}$ & 84 & 32.0 & 2.0 & 75 & 29.57 & 5.0 & 3.5 & Standard \\
\hline ZS-PDA12 & M & 24 & 13.5 & 3.0 & 55 & 9.19 & 6.0 & 4.0 & Standard \\
\hline ZS-PDA13 & M & 23 & 10.0 & 3.0 & 50 & 9.14 & 5.0 & 3.5 & Long \\
\hline ZS-PDA14 & M & 29 & 14.0 & 2.5 & 65 & 9.19 & 6.0 & 4.0 & Long \\
\hline ZS-PDA15 & $\mathrm{F}$ & 11 & 7.0 & 3.8 & 105 & 12.33 & 7.0 & 5.0 & Long \\
\hline ZS-PDA17 & $\mathrm{F}$ & 48 & 16.5 & 2.0 & 60 & 10.00 & 5.0 & 3.5 & Standard \\
\hline \multicolumn{10}{|l|}{ Type D PDA } \\
\hline ZS-PDA16 & F & 180 & 54.0 & 3.0 & 55 & 8.48 & 7.0 & 5.0 & Long \\
\hline \multicolumn{10}{|l|}{ Type E PDA } \\
\hline ZS-PDA09 & $\mathrm{F}$ & 15 & 9.5 & 3.0 & 75 & 11.40 & 6.0 & 4.0 & Standard \\
\hline
\end{tabular}

$\mathrm{kg}=$ kilograms; $\mathrm{mm}=$ millimeters; $\min =$ minutes.

months (range, 3-21 months), and all patients were reviewed at 1 month. All 18 devices were successfully implanted. All patients were discharged 24 hours following the procedure, and complete PDA occlusion on Doppler echocardiography was achieved in all but two patients (closure rate, 90\%). At 1-month follow-up, all patients had total duct occlusion on Doppler echocardiography (closure rate, 100\%).

Successful device placement rate was $100 \%$. There were no mortalities or major complications. Aortic disc bulging occurred in two patients without hemodynamic gradient. Mild pulmonary obstruction was noted in one patient in whom the long device variant was used. A cardiac ultrasound at 6-month follow-up did not show evidence of hemodynamic gradient. No blood transfusions were needed. No hemolysis occurred. There were no femoral vascular complications.

\section{Discussion}

\section{PDA Treatment}

PDA is a common congenital heart defect usually identified in early childhood. In some cases, it remains unrecognized until late in life. Currently, percutaneous closure of almost any PDA beyond neonatal age using detachable coils or specifically designed oc- 
cluders such as the ADO is the "gold standard" [3]. Despite the effectiveness of currently available devices, procedural challenges remain, especially when small infants and/or large PDAs are involved. Moreover, increasing experience with transcatheter techniques has resulted in interventional cardiologists attempting to more frequently treat patients who have PDAs with complex morphologies [6]. Therefore, there still is a demand for an ideal PDA closure device. Theoretically, such a device would have a design adaptable to any shape or size of PDA, regardless of patient age and weight, and achieve immediate closure in 100\% of cases. The implantation technique would also be operator-friendly. In addition to addressing current shortcomings, such a device would reduce the need for catheterization laboratories to stock several types of products with different sizes. These remaining unfulfilled needs justify ongoing research and development of new device models.

\section{The ODO Device}

The ODO device was developed with the aim of addressing some of the above-mentioned drawbacks. Even though our study was not comparative, the ODO device resembles the ADO I device with respect to design, intended use, and specific application, which provides an "experimental-feeling" comparison between the two devices. In fact, the ODO device material and delivery system and techniques are very similar to those of the ADO I. Notwithstanding these similarities, radical modifications in the shape of the ODO were introduced. The core of the device is wider at the pulmonary end than at the aortic end, the distal clamp at the aortic end (in the ADO) is not present, and the screw attachment protrudes from the pulmonary end. This shape, which resembles a champagne cork, takes advantage of the benefits of both the ADO I (i.e., inflexible connection between the aortic disc and device core) and the ADO II (i.e., aortic and pulmonary retention discs). In addition, retrieval of the device in case of accidental embolization is theoretically easier because the screw protrudes from the pulmonary end after release, making it more accessible for snaring.

Given that the ODO is available in larger sizes than the ADO devices, it allows closure of larger-sized PDAs. In fact, prior to the launch of the ODO, in some studies, patients with large PDAs had to be excluded due to non-availability of larger devices [7]. Another crucial difference from the ADO I is that the ODO comes in two length options: standard and long shank. The long variant may be needed in some "slow tapering" type A or nonconical long and large PDAs. In one patient in our series with a large $(3 \mathrm{~mm})$ and long (11 $\mathrm{mm}$ ) type D PDA, the ODO 5-7 long device was clearly the most suitable (Figure 2). Before the introduction of the ODO, our best option would have been to deploy an ADO I, including its aortic retention disc, in the PDA body. This was in fact successfully performed in a similar case in a previous study [3].

\section{Device Selection}

In the first few cases, the size of the aortic end of the occluder shank was chosen based on the narrowest diameter of the PDA, extrapolating our experience with the ADO I. After facing occurrences of aortic disc bulging (Figure 3), probably due to excessive oversizing, we concluded that the shank size should be calculated based on the part to be "squeezed" by the duct. It is worth mentioning that the choice of sizing should take into consideration the systolo-diastolic variations of the duct size, particularly in larger ducts (>3 mm) [8].

\section{Safety and Efficacy}

Reported case series in the literature confirm the high occlusive properties of the ODO, even though larger ducts usually require more time to close $[8,9]$. Our present results demonstrate a $100 \%$ success rate (shunt closure and successful implantation) with zero mortality and no serious morbidity. In fact, we noted a $90 \%$ closure rate at day 1 , reaching $100 \%$ at 1-month follow-up. In our series as well as a recently reported case series of PDA closure with the ODO device, no major adverse events (e.g., accidental device embolization, significant aortic or pulmonary obstruction, endocarditis, hemolysis or vascular injury) were encountered [10]. Considering the high degree of similarity between the Occlutech and Amplatzer devices and that most complications are seen during or shortly after implantation, it is reasonable to infer comparable safety of the two devices. Furthermore, reported late adverse events were very rare [11, 12], and therefore no further major adverse events are expected from studies of the ODO device. 
Due to the lack of a dedicated delivery system early in our study, some difficulties were noted while handling the device. We encountered the same drawbacks described by Kudumula et al. [8] and Rioz-Mendez [13] in term of loading and later detaching the device. Nevertheless, these difficulties had minimal impact on our procedure and fluoroscopy times due to the experience of the operator and his familiarity with the ADO, which led to bypassing a substantial amount of the learning curve [12]. Ten cases after the launch of our series, the manufacturers introduced important changes, providing a specific delivery system and thus minimizing further technical problems.

Although aortic embolization of the ADO I was rarely reported, as even relatively long ducts tend to shorten after being pulled back with the device, we found that some longer PDAs would not be appropriately closed with an ADO I and thus required the use of the long variant of the ODO to avoid aortic device dislodgment [3]. The case pictured in Figure 2 highlights the advantage of this variant. However, the long variant of the device can be a double-edged sword if the shortening of the duct after pullback is not taken into consideration. In one patient, the inappropriate use of this variant led to the protrusion of the device in the pulmonary artery with mild, insignificant gradient that completely resolved 6 months later.

Although our study is not comparative, and despite the small number of cases, our experience suggests that the ODO is a safe, effective, and operator-friendly device for PDA closure in patients weighing $\geq 6 \mathrm{~kg}$ with mostly type A PDA. The availability of two different length variants makes the ODO a preferable solution for some long and large type D PDAs. Larger case series and longer follow-up, as well as comparative studies, would provide additional support for our findings. It remains to be determined whether the ODO is capable of replacing all preexisting devices in all patients.

\section{Conflict of Interest}

The authors have no conflict of interest relevant to this publication.

\section{Comment on this Article or Ask a Question}

\section{References}

1. Porstmann W, Wierny L, Warnke H, Gerstberger G, Romaniuk PA. Catheter closure of patent ductus arteriosus: Sixty-two cases treated without thoracotomy. Radiol Clin North Am. 1971;9:203-218. PMID: 4938290

2. Porstmann W, Wierny L, Warnke H. Der Verschluss des Ductus Arteriosus in persistent ohne Thorakotomie Thoraxchirurgie. 1967;15:109-203.

3. Saliba Z, El-Rassi I, Helou D, Chehab G, Abdel-Massih T, Daou L, et al. Analyzing the failures of percutaneous closure of the patent ductus arteriosus in patients over $5 \mathrm{~kg}$. J Invasive Cardiol. 2012;24:434-438. PMID: 22954562

4. Baruteau $A E$, Hascoet $S$, Baruteau J, Boudjemline Y, Lambert V, Angel CY, et al. Transcatheter closure of patent ductus arteriosus: Past, present and future. Arch of Cardiovasc Dis. 2014;107:122-132. DOI: 10.1016/j.acvd.2014.01.008

5. Rao PS. Percutaneous closure of patent ductus arteriosus-current status. J Invasive Cardiol. 2011;23:517-520. PMID: 22147400

6. Saliba Z, El-Rassi I, Helou D, Abou-Jaoudeh
P, Chehab G, Daou L, et al. Development of catheter-based treatment of patent ductus arteriosus: a medium-sized centre experience. Arch Cardiovasc Dis. 2009;102:111118. DOI: 10.1016/j.acvd.2008.11.001

7. Al-Hamash SM, Wahab HA, Khalid ZH, Nasser IV. Transcatheter closure of patent ductus arteriosus using Ado device: Retrospective study of 149 patients. Heart Views. 2012;13:1-6. DOI: 10.4103/1995705X.96658

8. Kudumula V, Taliotis D, Duke C. The new occlutech duct occluder: immediate results, procedural challenges, and short-term follow-up. J Invasive Cardiol. 2015;27:250257. PMID: 25929302

9. Abdelbasit MA, Alwi M, Kandavello G, Che Mood M, Samion H, Hijazi ZM. The new Occlutech PDA occluder: Initial human experience. Catheter Cardiovasc Interv. 2015;86:94-99. DOI: $10.1002 / c c d .25878$

10. Jang GY, Son CS, Lee JW, Lee Jy, Kim SJ. Complications after transcatheter closure of patent ductus arteriosus. J Korean Med Sci. 2007;22:484-490. DOI: 10.3346/ jkms.2007.22.3.484

11. Abadir S, Boudjemline Y, Rey C, Petit J, Sassolas F, Acar P, et al. Significant persistent ductus arteriosus in infants less or equal to $6 \mathrm{~kg}$ : Percutaneous closure or surgery? Arch Cardiovasc Dis. 2009;102:533-540. DOI: 10.1016/j.acvd.2009.04.004

12. Saliba Z, El-Rassi I, Abi-Warde MT, Chehab G, Daou L, Khater D, et al. The Amplatzer Duct Occluder II: a new device for percutaneous ductus arteriosus closure. J Interv Cardiol 2009;22:496-502. DOI: 10.1111/j.1540-8183.2009.00504.x

13. Ríoz-Méndez RE. The New Occlutech Duct Occluder. J Invasive Cardiol. 2015;27:E229.

Cite this article as: Hanna $N$, Charbel R, Chehab G, Gerbaka B, Saliba Z. The Occlutech Duct Occluder for Patent Ductus Arteriosus. Structural Heart Disease. 2017;3(1):1-7. DOI: http:// dx.doi.org/10.12945/j.jshd.2017.16.002 